\title{
Meta-analysis and trial sequential analysis of LncRNA H19 polymorphic variants on susceptibility to cancer
}

\section{Kunpeng Wang}

Department of Urology, The First People's Hospital of Lianyungang, Lianyungang Clinical Medical College of Nanjing Medical University, Lianyungang

Zheng Zhu

First Clinical Medical College of Nanjing Medical University

Yiqiu Wang

Department of Surgical Oncology, Xuzhou Central Hospital, Southeast University Cancer Institute, Xuzhou, Jiangsu

Dayuan Zong

Department of Urology, The First People's Hospital of Lianyungang, Lianyungang Clinical Medical College of Nanjing Medical University, Lianyungang

Peng Xue

Department of Urology, The First People's Hospital of Lianyungang, Lianyungang Clinical Medical College of Nanjing Medical University, Lianyungang Jinbao Gu

Department of Urology, The First People's Hospital of Lianyungang, Lianyungang Clinical Medical College of Nanjing Medical University, Lianyungang Daoyuan Lu

Department of Urology, The First People's Hospital of Lianyungang, Lianyungang Clinical Medical College of Nanjing Medical University, Lianyungang Chuanquan Tu ( $\sim$ tuchuanquan1116@126.com)

\section{Research article}

Keywords: LncRNA H19; Cancer; Polymorphism; Susceptibility; Meta-analysis.

Posted Date: March 9th, 2020

DOl: https://doi.org/10.21203/rs.3.rs-16371/v1

License: (9) (1) This work is licensed under a Creative Commons Attribution 4.0 International License. Read Full License 


\section{Abstract}

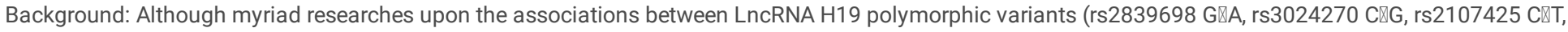
rs2735971 A囚G and rs217727 GهA) and the susceptibility to cancer have been conducted, these results remained contradictory and perplexing. Basing on that, a systematic review and updated meta-analysis was conducted to anticipate a fairly precise assessment about these associations. Methods: We retrieved the electronic databases EMBASE, PubMed and Web of Science for valuable academic studies before October 1st, 2019. Ultimately, 24 of which were encompassed after screening, and the available data was extracted and integrated. The pooled odds ratios (ORs) with $95 \%$ confidence intervals (Cls) was adopted to evaluate the strength of these associations. For multi-level investigation, subgroup analysis derived from source of controls together with genotypic method was preformed. Eventually, 24 articles altogether embodying 52 studies were included. Results: The results illuminated that LncRNA H19 SNPs mentioned above were all irrelevant to cancer susceptibility. Nevertheless, crucial results were found concentrated in population-based control group when subgroup analysis by source of controls were performed in $\mathrm{H} 19$ mutation rs2839698 and rs2735971. Meanwhile, in the stratification analysis by genotypic method, apparent cancer risks were discovered by TaqMan method in H19 mutation rs2107425 and rs 3024270 . Then, trial sequential analysis (TSA) demonstrated that the results about such associations were firm evidence of effect, except rs2735971 polymorphism. Conclusion: Therefore, this metaanalysis indicated that LncRNA H19 SNPs were not associated with the susceptibility to human cancer. However, after the stratification analysis, inconsistent results still existed in different genotypic method and source of control. Thus, more high-quality studies on cancer patients of different factors were needed to confirm these findings.

\section{Background}

Continuously threatening public health worldwidle, malignant tumor has long been the second biggest cause of death in the developed countries. 1,762,450 new cancer cases and 606,880 cancer mortalities are predicted to occur in the USA in 2019[1]. Nevertheless, the pathogeny of malignant tumor still remains vague. Consensus amongst worldwide researchers is that both the environmental and genetic abnormality contribute to the carcinogenesis[2]. The aberration of genetic expression increases the risk of the initiation and progression of cancer[3]. Accumulating studies have been focusing on the repercussions of long non-uncoding RNA (IncRNA) mutation which has a place in the genetic factors mentioned above[4-7].

$\mathrm{H} 19$ is a $2.3 \mathrm{~kb}$ IncRNA without the open reading frames, located in chromosome 11p15.5 [8]. The H19 gene, which is maternal imprinted and expressed, plays an irreplaceable role during embryonic phase and decreases in postpartum mature tissues[9]. As we know, LncRNA H19 is considered as a vital factor associated with, cancer susceptibility included, various biological process which impacts the invasion, metastasis, recurrence and poor prognosis of cancer[10]. It might extend the influence upon the development and progression of disease through the regulation of expression on and after transcription of the oncogene and antioncogene[11]. An increasing amount of researches have found the up-regulation of $\mathrm{H} 19$ gene in almost overall cancer, such as breast cancer, bladder cancer, gastric cancer, hepatocellular cnacer and so on[4-7;12].

Single nucleotide polymorphisms (SNPs), a type of genetic mutation, affect the gene expression and function, accordingly causing carcinogenesis[13]. Previous studies have indicated the associations between the risks of cancer and several SNPs (rs2839698 GロA, rs3024270 C口G, rs2107425 C口T, rs2735971 $A \llbracket G$ and rs217727 GロA)[14-18]. For instance, Wang et al. conducted a study and found that H19 polymorphism rs217727 might influence the susceptibility to non-small cell lung cancer[19]. However, another study conducted by Lv et al. showed no association between $\mathrm{H} 19$ polymorphism rs217727 and overall cancer susceptibility was found[20]. In that case, though considerable researches have been performed, pooled results seem to be conflicting. Herein, this metaanalysis aimed at deriving a more accurate evaluation in all relevant published studies of the associations between the H19 SNPs and overall cancer susceptibility.

\section{Materials And Methods}

We conprehensively retrieved the electronic databases EMBASE, PubMed and Web of Science for all relevant articles published before January 1st, 2020, utilizing terms including 'H19 gene', 'polymorphisms' or 'genetic mutation' with 'LncRNA' or 'H19 SNPs', and 'cancer susceptibility' or 'tumor'. Potential eligible studies were collected and integrated by manual work. Additionally, we then removed the duplicate data from different articles.

Meanwhile, the remaining articles were screened by following criteria: (1) Presented original data from case-control or cohort studies; (2) Existing one or more relevant H19 SNPs (rs2839698 G『A, rs3024270 C『G, rs2107425 C囚T, rs2735971 A囚G and rs217727 G『A); (3) Enrolled patients with cancer histopathological diagnosis definitely, and control groups without primary malignancy; (4) Availability of subgroup analysis statistical data of both cases and controls. Correspondingly, the studies enrollment followed these exclusive criteria: (1) Without available data; (2) Without valuable results related to H19; (3) No casecontrol study.

\section{Data extraction}

The available data from articles after screening were extracted and integrated respectively by two investigators (KP Wang and Z Zhu). Upon the appearance of divergence, a third investigator (YQ Wang) would take intervention. All the data collected were integrated in an united form, especially with regard to the following information: First author's name, Publication year, Ethnicity, Source of controls, Genotypic method, The number of cases and controls, The number of $\mathrm{H} 19$ polymorphisms carriers and non-carriers respectively as well as The results of the Hardy-Weinberg equilibrium test.

\section{Statistical analysis}

In the meta-analysis, the ORs with $95 \%$ Cls were used to estimate the strength of the associations between the H19 SNPs and cancer susceptibility, and comparisons of the allele, homozygous, heterozygous, dominant and recessive model were applied. Q-test and $\mathrm{I}^{2}$ statistic were used to assess heterogeneity 
across sutdies. $I^{2}<50 \%$ suggested no obvious heterogeneity, in which case fixed effect model should be selected for calculation; only $\mathrm{I}^{2} \geqq 50 \%$ should the random effect model be selected. Generally, several factors, such as experimental scheme, sex, age, ethnicity, genotypic method and so on, could stimulate the heterogeneity. Therefore, subgroup analysis derived from source of controls and method of genotyping was conducted, aiming at investigating the source of heterogeneity. The Hardy-Weinberg equilibrium (HWE) test was adopted in the control groups to evaluate the gene and genotype frequency, and P value exceeded 0.05 , guaranteeing a significant equilibrium. In addition, considering the examination of the stability and reliability of the results, sensitive analysis was adopted through consecutively omitting one study per time. Meanwhile, we conducted both Egger's test and Begg's funnel plots in order to verify the publication bias among these studies Statistical data was analyzed through Stata statistical software (Version 12.0, Stata Corporation, College Station, TX, USA).

\section{Trial sequential analysis}

The results of the meta-analysis should relate the total number of randomized participants accounting for statistical diversity to avoid type I errors. Thus, TSA was performed to estimate the required information size. TSA could confirm greater statistical data reliability through modifying the threshold with dispersive data for significance level. We then calculated the required information size and constructed the trial sequential monitoring boundaries (the sloping red line). If the blue line (representing the cumulative Z-curve) crossed the sloping red line or exceeded the vertical red line (representing the information size required), a sufficient information size would be guaranteed and crucial result would be reached. On the contrary, either of the red line not being reached reveals that additional clinical trials were necessary to guarantee the sufficient information size for further verification. The TSA software (TSA, version 0.9, 2011; Copenhagen Trial Unit, Copenhagen, Denmark) was adopted in this study.

\section{Results}

\section{Studies characteristics}

Primitively, a total of 182 articles were collected under the guidance of the retrieve strategy above for further screening. Then, 24 articles containing 52 studies met the inclusive criteria, ranging from Feburary 2008 to July 2019 as for publish date[15-16;21-33]. The flow pathway was shown in Figure 1. [3440]Distribution of the genotypes in the controls satisfied with HWE. The baseline characteristics of all the studies were extracted and tabulated in Table 1. Asians, Caucasians, Africans and Mixed were involved in these studies. We separated these studies into population-based (PB) and hospital-based (HB) groups to help differentiate between various sources of control. Moreover, the studies collected performed eight genotypic methods altogether, for instance, Illumina, Taqman, Sequenom, etc.

Meanwhile, we calculated the pooled ORs and 95\% Cls using five genetic model in order to assess the association between IncRNA H19 ploymorphisms and cancer susceptibility, results of which were tabulated in Table 2. Also, stratification analysis by source of controls along with genotypic method was applied to investigate the heterogeneity of all studies.

\section{rs2839698 GロA and cancer susceptibility}

Thirteen studies about IncRNA H19 rs2839698 G $₫$ A ploymorphism and the susceptibility to cancer consisting 7,351 cases and 10,066 controls met the inclusive criteria. The pooled ORs were 1.08 (95\% Cl: 0.98-1.19) for allele model, 1.08 (95\% Cl: 0.96-1.23) for dominant model, 1.06 (95\% Cl: 0.94-1.20) for homozygote model, 1.15 (95\% Cl: 0.94-1.41) for heterozygote model and 1.12 (95\% Cl: 0.96-1.31) for recessive model (Figure 2). Despite of no positive results, significant association between rs2839698 G凶A and cancer susceptibility in population-based controls (allele model: OR=1.17, 95\% Cl: 1.04-1.31; homozygote model: OR=1.41, 95\% Cl: 1.04-1.91; recessive model: OR=1.46, 95\% Cl: 1.13-1.89) was observed in the stratification analysis by source of control. In addition, no significant results were detected in the subgroup analysis as to the methods of genotyping.

\section{rs217727 GロA and cancer susceptibility}

Herein, 15 Studies focusing on rs 217727 G $₫ A$ polymorphism and cancer susceptibility included 8,164 cases and 10,963 controls. No significant association was indicated through the pooled risk estimation under allele model $(\mathrm{OR}=1.03,95 \% \mathrm{Cl}=0.94-1.13)$, dominant model $(\mathrm{OR}=1.06,95 \% \mathrm{Cl}=0.93-1.22)$, heterozygous model ( $\mathrm{OR}=1.07,95 \% \mathrm{Cl}=0.92-1.23)$, homozygous model $(\mathrm{OR}=1.02,95 \% \mathrm{Cl}=0.85-1.21)$ and recessive model $(\mathrm{OR}=0.99,95 \% \mathrm{Cl}=0.84-1.16)(\mathrm{Figure} 3)$. Besides, no positive results were observed in either of the subgroup analysis by source of control and genotypic method.

\section{rs2107425 CDT and cancer susceptibility}

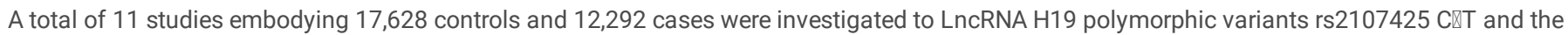
susceptibility to cancer. Analogously, no significant association between rs $2107425 \mathrm{C} \otimes \mathrm{T}$ polymorphism and cancer risk was shown in the meta-analysis according to the pooled ORs of these studies under allele model (OR=0.96, 95\% $\mathrm{Cl}=0.89-1.04)$, dominant model $(\mathrm{OR}=0.95,95 \% \mathrm{Cl}=0.85-1.06)$, heterozygous model (OR=0.95, 95\% Cl=0.84-1.07), homozygous model ( $\mathrm{OR}=0.97,95 \% \mathrm{Cl}=0.83-1.13)$ and recessive model $(\mathrm{OR}=0.98,95 \% \mathrm{Cl}=0.87-1.12)(\mathrm{Figure} 4)$. Nevertheless, as to the stratification analysis of genotypic method, the result was significant only in TaqMan (allele model: OR=0.86, 95\% $\mathrm{Cl}=0.80-0.94$ ), while no significant results was detected in subgroup of source of control.

\section{rs2735971 A]G and cancer susceptibility}

The present meta-analysis enrolled 4,393 controls and 3,522 cases from a sum of six studies on rs2735971 A『G polymorphism and cancer susceptibility. No significant association was observed among these studies (allele model (OR=0.91, 95\% $\mathrm{Cl}=0.75-1.11)$, dominant model $(\mathrm{OR}=0.72,95 \% \mathrm{Cl}=0.44-1.17)$, heterozygous model $(\mathrm{OR}=0.68,95 \% \mathrm{Cl}=0.41-1.13)$, homozygous model $(\mathrm{OR}=0.76,95 \% \mathrm{Cl}=0.45-1.29)$ and recessive model $(\mathrm{OR}=0.99,95 \% \mathrm{Cl}=0.89-1.11)$ ) 
(Figure 5). Additionally, the results of stratified analysis by genotypic method were not positive. By contrast, in subgroup analysis by source of control, feebly positive results were shown in PB control with (dominant model: OR=0.85, 95\% $\mathrm{Cl}=0.71-1.00$; heterozygous model: OR=083, 95\% $\mathrm{Cl}=0.70-0.99$ ).

\section{rs3024270 CDG and cancer susceptibility}

No significant association existed between rs 3024270 mutation and cancer susceptibility as shown by the pooled risks of 8 relevant studies consisting 4,211 cases and 6,014 controls under allele model $(\mathrm{OR}=1.03,95 \% \mathrm{Cl}=0.98-1.10)$, dominant model $(\mathrm{OR}=1.07,95 \% \mathrm{Cl}=0.97-1.18)$, heterozygous model(OR=1.05, 95\% $\mathrm{Cl}=0.95-1.17)$, homozygous model $(\mathrm{OR}=1.09,95 \% \mathrm{Cl}=0.97-1.23)$ and recessive model $(\mathrm{OR}=1.03,95 \% \mathrm{Cl}=0.94-1.13)($ Figure 6). However, stratification analysis by source of control indicated significant association with cancer susceptibility in the PB control group (homozygous model: OR=1.28, 95\% $\mathrm{Cl}=1.01-1.61$ ). Additionally, the results of analysis stratified by genotypic method were more significant while using TaqMan than non-TaqMan methods (allele model: $\mathrm{OR}=1.08,95 \% \mathrm{Cl}=1.01-1.16$, dominant model: $\mathrm{OR}=1.12,95 \% \mathrm{Cl}=1.00-1.26$ and homozygous model: $\mathrm{OR}=1.21,95 \% \mathrm{Cl}=1.05-1.39$ ).

\section{Sensitivity analysis}

We performed sensitivity analysis by excluding single eligible study sequentially to detect individual study's influence on the pooled results. According to the results, no single study was found affect the pooled OR in the allele model, suggesting a statistically robust results (Figure 7).

\section{Publication bias}

Both Egger's test and Begg's funnel plot were utilized in the selected literature. With the symmetrical shapes of funnel plots shown in Figure 8, the absence of publication bias could be testified in the allele model (rs2839698: $P=0.222$, rs217727: $P=0.882$, rs 2107425: $P=0.421$, rs2735971: $P=0.851$ and rs3024270: $P=0.322)$.

\section{Trial sequential analysis results}

In this meta-analysis, Figure 9 showed that the information sizes of all the H19 mutations investigated were sufficient except rs2735971 A『G polymorphism,

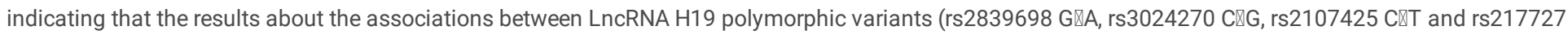
$\mathrm{G} \llbracket \mathrm{A}$ ) and the susceptibility to cancer were firm evidence of effect, and the further verification is necessary for the relationship of rs2735971 AखG mutation and cancer risk.

\section{Discussion}

An growing amount of researches have been focusing on the mutation of $\mathrm{H} 19$ when it comes to the genesis and development of various cancer[41]. As a long non-coding RNA, $\mathrm{H} 19$ lacks the open reading frame to translate protein whose end product is RNA sequence and can participate in downstream RNA regulatory[21;42]. LncRNA H19 is an imprinted gene the aberrant expression of which is associated with cancer susceptibility[22]. In this meta-analysis, SNPs

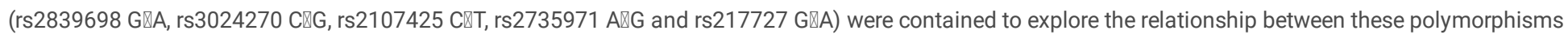
and the risk of cancer.

Previously, several meta-analysis on aberration of $\mathrm{H} 19$ have been conducted thanks to the identification of numerous IncRNAs[23-24]. Though the results were contrary to many studies, a meta-analysis conducted by Lv et al. revealed that rs217727 were uncorrelated to overall cancer risk[20]. It might account for the lack of the interactive microRNAs (miRNAs) which could influence the regulation and modification of IncRNAs SNPs directly[20;43]. In that case, the site where structural gene alteration (such as mutation, deletion, insertion etc) caused by the SNPs might be at variance with the binding position of miRNAs that regulate IncRNA expression, thus indicating no significant association with overall cancer risk. Also, another meta-analysis conducted by Li et al. inspired us on the possible reason[44]. The various cancer location and patient ethnicity probably account for the discrepancies amongst these studies. In these studies, a small sample size and controversial results caused by the former factor might make these analysis relatively unreliable. Herein, we conducted this metaanalysis with the largest sample capacity and the most up-to-date studies and data, comprehensively analyzing all literatures to study such association. According to quantitative synthesis results, all the mutation mentioned above were found no significant association.

While stratified by source of control, significant association was found in the PB control group between rs2839698, rs2735971 and rs3024270 polymorphisms and the susceptibility to cancer, whereas no significant results were detected in their HB control group. Lack of the representativeness might account for the phenomena. Moreover, referring to subgroup analysis of genotypic method, significant association was also detected between the risk of cancer and rs2107425, rs3024270 polymorphisms adopting TaqMan method for genotyping, whereas similar results were not found while using other genotypic methods. The possible reason might be that different genotypic methods lead to different statistical results owing to their relative merits. The merits of TaqMan are the lower probability of PCR pollution due to that the reaction happens in PCR process, avoiding separation and elution[45].

TSA, as an statistical tool, is similar to interim analysis in a single trial, where trial monitoring boundaries are drawn for each outcome whether to continue additional trials to assess for evidence while a $\mathrm{P}$ value is small enough to show the projected effect or for futility[46]. The association shown in the results of this meta-analysis could be unreliable accounting for limited data. Therefore, TSA was adopted in order to diminish the probability of type I error and verify whether the evidence of our results was adequate or not. The results about the associations between LncRNA H19 polymorphic variants (rs2839698, rs217727, rs2107425 and rs3024270) and the susceptibility to cancer were firm evidence of effect. However, the cumulative Z-curve of H19 rs2735971 polymorphism neither crossed the trial sequential monitoring boundary nor exceeded the required information size, indicating that false positive results might be eliminated in advance due to repeated significance testing and random errors in meta-analysis[47]. In order to obtain results with firm evidence, further verification is necessary. 
Inevitably, several additional limitations should be warranted in this meta-analysis. (1). As a multifactorial disease, overall cancers are influenced by genetic combined with environmental factors. Focusing on single gene region, this meta-analysis ignored the complex interaction between various factors, in which case the association was unilateral; (2). The scale of studies collected was fairly narrow, referring to the subgroup analysis. Also, the amount of these studies needs to be expanded. Subgroups with less than three studies were retained, thus might causing the potential false associations; (3). The ethnicities of studies were concentrated on Asian, which means the results might not applicable for all population. Hence, to ensure reliability of our meta-analysis, attention must be paid to the influence of various factors in the future studies of more large-sample, multi-center and high-quality researches.

\section{Conclusion}

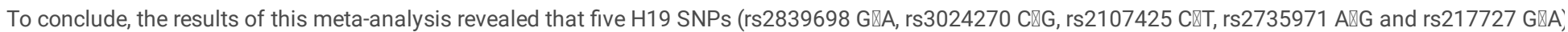
had no significant association with the overall cancer susceptibility, thereby suggesting that $\mathrm{H} 19$ might not have clinical significance in cancer diagnosis and treatment. However, after the stratification analysis, inconsistent results still existed in different genotypic method and source of control. Thus, more highquality studies on cancer patients of different factors were needed to confirm these findings.

\section{Abbreviations}

TSA, Trial sequential analysis;

LncRNA, Long non-uncoding RNA;

SNP, Single nucleotide polymorphisms;

miRNA, microRNAs;

HWE, Hardy-Weinberg equilibrium;

ORs, Odds ratios;

Cls, Confidence intervals.

\section{Declarations}

\section{Ethics approval and consent to participate}

None declared.

\section{Consent for publication}

Written informed consent for publication was obtained from all participants.

\section{Availability of data and material}

All data on which the conclusions rely are either deposited in publicly available repositories or presented in the main papers or additional supporting files.

\section{Competing interests}

We declare that we have no conflict of interest.

\section{Authors' contributions}

Protocol/project development: CQ Tu, KP Wang and Z Zhu

Data collection or management: Z Zhu, JB Gu and KP Wang

Data analysis: YQ Wang, DY Zong and P Xue

Manuscript writing/editing: Z Zhu, DY Lu and KP Wang.

All authors have read and approved the manuscript.

\section{Acknowledgements}

No funding or financial support was received for this study.

\section{References}

1. Siegel RL, Miller KD, Jemal A: Cancer statistics, 2019. CA Cancer J Clin 2019, 69(1):7-34. 
2. Chu M, Yuan W, Wu S, Wang Z, Mao L, Tian T, Lu Y, Zhu B, Yang Y, Wang B et al: Quantitative assessment of polymorphisms in H19 IncRNA and cancer risk: a meta-analysis of 13,392 cases and 18,893 controls. Oncotarget 2016, 7(48):78631-78639.

3. Chen G, Wang Z, Wang D, Qiu C, Liu M, Chen X, Zhang Q, Yan G, Cui Q: LncRNADisease: a database for long-non-coding RNA-associated diseases. NUCLEIC ACIDS RES 2013, 41(Database issue):D983-D986.

4. Matouk IJ, Raveh E, Abu-lail R, Mezan S, Gilon M, Gershtain E, Birman T, Gallula J, Schneider T, Barkali M et al: Oncofetal H19 RNA promotes tumor metastasis. Biochim Biophys Acta 2014, 1843(7):1414-1426.

5. Yan J, Huang X, Zhang X, Chen Z, Ye C, Xiang W, Huang Z: LncRNA LINC00470 promotes the degradation of PTEN mRNA to facilitate malignant behavior in gastric cancer cells. Biochem Biophys Res Commun 2019.

6. Guo X, Wei Y, Wang Z, Liu W, Yang Y, Yu X, He J: LncRNA LINC00163 upregulation suppresses lung cancer development though transcriptionally increasing TCF21 expression. AM J CANCER RES 2018, 8(12):2494-2506.

7. Meng L, Ma P, Cai R, Guan Q, Wang M, Jin B: Long noncoding RNA ZEB1-AS1 promotes the tumorigenesis of glioma cancer cells by modulating the miR200c/141-ZEB1 axis. AM J TRANSL RES 2018, 10(11):3395-3412.

8. Matouk IJ, DeGroot N, Mezan S, Ayesh S, Abu-lail R, Hochberg A, Galun E: The H19 non-coding RNA is essential for human tumor growth. PLOS ONE 2007, 2(9):e845.

9. Matouk I, Ayesh B, Schneider T, Ayesh S, Ohana P, De-Groot N, Hochberg A, Galun E: Oncofetal splice-pattern of the human H19 gene. Biochem Biophys Res Commun 2004, 318(4):916-919.

10. Wang KC, Chang HY: Molecular mechanisms of long noncoding RNAs. MOL CELL 2011, 43(6):904-914.

11. Liu L, Yang J, Zhu X, Li D, Lv Z, Zhang X: Long noncoding RNA H19 competitively binds miR-17-5p to regulate YES1 expression in thyroid cancer. FEBS J 2016, 283(12):2326-2339.

12. Luo M, Li Z, Wang W, Zeng Y, Liu Z, Qiu J: Long non-coding RNA H19 increases bladder cancer metastasis by associating with EZH2 and inhibiting Ecadherin expression. CANCER LETT 2013, 333(2):213-221.

13. Niu YM, Du XY, Lu MY, Xu QL, Luo J, Shen M: Significant association between functional microRNA polymorphisms and head and neck cancer susceptibility: a comprehensive meta-analysis. Sci Rep 2015, 5:12972.

14. Lu Y, Tan L, Shen N, Peng J, Wang C, Zhu Y, Wang X: Association of IncRNA H19 rs217727 polymorphism and cancer risk in the Chinese population: a meta-analysis. Oncotarget 2016, 7(37):59580-59588.

15. Abdollahzadeh S, Ghorbian S: Association of the study between LncRNA-H19 gene polymorphisms with the risk of breast cancer. J CLIN LAB ANAL 2019, 33(3):e22826.

16. Cui P, Zhao Y, Chu X, He N, Zheng H, Han J, Song F, Chen K: SNP rs2071095 in LincRNA H19 is associated with breast cancer risk. Breast Cancer Res Treat 2018, 171(1):161-171.

17. Wu ER, Chou YE, Liu YF, Hsueh KC, Lee HL, Yang SF, Su SC: Association of IncRNA H19 Gene Polymorphisms with the Occurrence of Hepatocellular Carcinoma. Genes (Basel) 2019, 10(7).

18. Yang PJ, Hsieh MJ, Hung TW, Wang SS, Chen SC, Lee MC, Yang SF, Chou YE: Effects of Long Noncoding RNA H19 Polymorphisms on Urothelial Cell Carcinoma Development. Int J Environ Res Public Health 2019, 16(8).

19. Wang G, Liu Q, Cui K, Ma A, Zhang H: Association between H19 polymorphisms and NSCLC risk in a Chinese Population. J BUON2019, $24(3)$ :913-917.

20. Lv Z, Xu Q, Yuan Y: A systematic review and meta-analysis of the association between long non-coding RNA polymorphisms and cancer risk. Mutat Res $2017,771: 1-14$

21. Li S, Hua Y, Jin J, Wang H, Du M, Zhu L, Chu H, Zhang Z, Wang M: Association of genetic variants in IncRNA H19 with risk of colorectal cancer in a Chinese population. Oncotarget 2016, 7(18):25470-25477.

22. Verhaegh GW, Verkleij L, Vermeulen SH, den Heijer M, Witjes JA, Kiemeney LA: Polymorphisms in the H19 gene and the risk of bladder cancer. EUR UROL 2008, 54(5):1118-1126.

23. Gong WJ, Peng JB, Yin JY, Li XP, Zheng W, Xiao L, Tan LM, Xiao D, Chen YX, Li X et al: Association between well-characterized lung cancer IncRNA polymorphisms and platinum-based chemotherapy toxicity in Chinese patients with lung cancer. ACTA PHARMACOL SIN 2017, 38(4):581-590.

24. Hu P, Qiao O, Wang J, Li J, Jin H, Li Z, Jin Y: rs1859168 A \&gt; C polymorphism regulates HOTTIP expression and reduces risk of pancreatic cancer in a Chinese population. WORLD J SURG ONCOL 2017, 15(1):155.

25. Chu H, Chen Y, Yuan Q, Hua Q, Zhang X, Wang M, Tong N, Zhang W, Chen J, Zhang Z: The HOTAIR, PRNCR1 and POLR2E polymorphisms are associated with cancer risk: a meta-analysis. Oncotarget 2017, 8(26):43271-43283.

26. Gong WJ, Yin JY, Li XP, Fang C, Xiao D, Zhang W, Zhou HH, Li X, Liu ZQ: Association of well-characterized lung cancer IncRNA polymorphisms with lung cancer susceptibility and platinum-based chemotherapy response. Tumour Bio/ 2016, 37(6):8349-8358.

27. Hua Q, Lv X, Gu X, Chen Y, Chu H, Du M, Gong W, Wang M, Zhang Z: Genetic variants in IncRNA H19 are associated with the risk of bladder cancer in a Chinese population. MUTAGENESIS 2016, 31(5):531-538.

28. Xia Z, Yan R, Duan F, Song C, Wang P, Wang K: Genetic Polymorphisms in Long Noncoding RNA H19 Are Associated With Susceptibility to Breast Cancer in Chinese Population. Medicine (Baltimore) 2016, 95(7):e2771.

29. Yang ML, Huang Z, Wang Q, Chen HH, Ma SN, Wu R, Cai WS: The association of polymorphisms in IncRNA-H19 with hepatocellular cancer risk and prognosis. Biosci Rep 2018, 38(5). 
30. Yin Z, Cui Z, Li H, Li J, Zhou B: Polymorphisms in the H19 gene and the risk of lung Cancer among female never smokers in Shenyang, China. BMC CANCER 2018, 18(1):893.

31. Guo QY, Wang H, Wang Y: LncRNA H19 polymorphisms associated with the risk of OSCC in Chinese population. Eur Rev Med Pharmacol Sci 2017, 21(17):3770-3774.

32. He TD, Xu D, Sui T, Zhu JK, Wei ZX, Wang YM: Association between H19 polymorphisms and osteosarcoma risk. Eur Rev Med Pharmacol Sci 2017, 21(17):3775-3780.

33. Safari MR, Mohammad RF, Dehghan A, Noroozi R, Taheri M, Ghafouri-Fard S: Genomic variants within the long non-coding RNA H19 confer risk of breast cancer in Iranian population. GENE 2019, 701:121-124.

34. Li Z, Niu Y: Association between IncRNA H19 (rs217727, rs2735971 and rs3024270) polymorphisms and the risk of bladder cancer in Chinese population. MINERVA UROL NEFROL 2019, 71(2):161-167.

35. Yang C, Tang R, Ma X, Wang Y, Luo D, Xu Z, Zhu Y, Yang L: Tag SNPs in long non-coding RNA H19 contribute to susceptibility to gastric cancer in the Chinese Han population. Oncotarget 2015, 6(17):15311-15320.

36. Butt S, Harlid S, Borgquist S, Ivarsson M, Landberg G, Dillner J, Carlson J, Manjer J: Genetic predisposition, parity, age at first childbirth and risk for breast cancer. BMC Res Notes 2012, 5:414.

37. Barnholtz-Sloan JS, Shetty PB, Guan X, Nyante SJ, Luo J, Brennan DJ, Millikan RC: FGFR2 and other loci identified in genome-wide association studies are associated with breast cancer in African-American and younger women. CARCINOGENESIS 2010, 31(8):1417-1423.

38. Quaye L, Tyrer J, Ramus SJ, Song H, Wozniak E, DiCioccio RA, McGuire V, Hogdall E, Hogdall C, Blaakaer J et al: Association between common germline genetic variation in $\mathbf{9 4}$ candidate genes or regions and risks of invasive epithelial ovarian cancer. PLOS ONE 2009, 4(6):e5983.

39. Song H, Ramus SJ, Kjaer SK, DiCioccio RA, Chenevix-Trench G, Pearce CL, Hogdall E, Whittemore AS, McGuire V, Hogdall C et al: Association between invasive ovarian cancer susceptibility and 11 best candidate SNPs from breast cancer genome-wide association study. HUM MOL GENET 2009, 18(12):2297-2304.

40. Bhatti P, Doody MM, Alexander BH, Yuenger J, Simon SL, Weinstock RM, Rosenstein M, Stovall M, Abend M, Preston DL et al: Breast cancer risk polymorphisms and interaction with ionizing radiation among U.S. radiologic technologists. Cancer Epidemiol Biomarkers Prev 2008, 17(8):2007-2011.

41. Raveh E, Matouk IJ, Gilon M, Hochberg A: The H19 Long non-coding RNA in cancer initiation, progression and metastasis - a proposed unifying theory. MOL CANCER 2015, 14:184.

42. Wang L, Cai Y, Zhao X, Jia X, Zhang J, Liu J, Zhen H, Wang T, Tang X, Liu Y et al: Down-regulated long non-coding RNA H19 inhibits carcinogenesis of renal cell carcinoma. NEOPLASMA 2015, 62(3):412-418.

43. Qian B, Wang DM, Gu XS, Zhou K, Wu J, Zhang CY, He XY: LncRNA H19 serves as a ceRNA and participates in non-small cell lung cancer development by regulating microRNA-107. Eur Rev Med Pharmacol Sci 2018, 22(18):5946-5953.

44. Li XF, Yin XH, Cai JW, Wang MJ, Zeng YQ, Li M, Niu YM, Shen M: Significant association between IncRNA H19 polymorphisms and cancer susceptibility: a meta-analysis. Oncotarget 2017, 8(28):45143-45153.

45. Brentani RR, Carraro DM, Verjovski-Almeida S, Reis EM, Neves EJ, de Souza SJ, Carvalho AF, Brentani H, Reis LF: Gene expression arrays in cancer research: methods and applications. Crit Rev Oncol Hematol 2005, 54(2):95-105.

46. Wetterslev J, Thorlund K, Brok J, Gluud C: Trial sequential analysis may establish when firm evidence is reached in cumulative meta-analysis. $J$ CLIN EPIDEMIOL 2008, 61(1):64-75.

47. Devereaux PJ, Beattie WS, Choi PT, Badner NH, Guyatt GH, Villar JC, Cina CS, Leslie K, Jacka MJ, Montori VM et al: How strong is the evidence for the use of perioperative beta blockers in non-cardiac surgery? Systematic review and meta-analysis of randomised controlled trials. BMJ 2005, 331(7512):313321.

\section{Tables}


Table 1. Characteristics of individual studies included in the meta-analysis.

\begin{tabular}{|c|c|c|c|c|c|c|c|c|c|}
\hline Year & Surname & Ethnicity & $\mathrm{SOC}$ & Genotyping & Type & Cases & Controls & Gene polymorphism & HWE \\
\hline$\overline{2019}$ & Wang & Asian & HB & TaqMan & LC & 564 & 1536 & rs2839698』rs217727 & $\bar{Y}$ \\
\hline 2019 & $\mathrm{Li}$ & Asian & HB & TaqMan & $\mathrm{BC}$ & 200 & 200 & rs217727凹rs2735971』rs3024270 & Y \\
\hline 2019 & Mohammad & Asian & HB & 4P-ARMSPCR & $\mathrm{BCa}$ & 111 & 130 & rs2839698』rs217727 & $\mathrm{Y}$ \\
\hline 2019 & $\mathrm{Wu}$ & Asian & HB & TaqMan & HCC & 359 & 1190 & 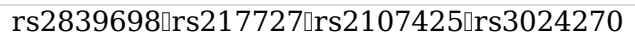 & $\mathrm{Y}$ \\
\hline 2019 & Yang & Asian & HB & PCR & $\mathrm{BC}$ & 431 & 431 & 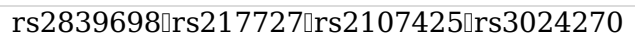 & $\mathrm{Y}$ \\
\hline 2018 & Yang & Asian & HB & KASP & $\mathrm{HCC}$ & 472 & 472 & rs2839698』rs2735971ロrs3024270 & $\mathrm{Y}$ \\
\hline 2018 & Cui & Asian & HB & TaqMan & $\mathrm{BCa}$ & 1491 & 1677 & rs2839698』rs217727 & $\mathrm{Y}$ \\
\hline 2018 & Yin & Asian & $\mathrm{PB}$ & Illumina & LC & 556 & 395 & rs217727ロrs2107425 & $\mathrm{Y}$ \\
\hline 2018 & Abdollahzadeh & Asian & HB & PCR-RFLP & $\mathrm{BCa}$ & 150 & 100 & rs217727 & Y \\
\hline 2017 & Guo & Asian & HB & Illumina & OSCC & 362 & 741 & 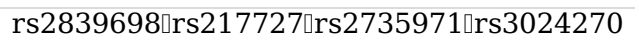 & $\mathrm{Y}$ \\
\hline 2017 & $\mathrm{He}$ & Asian & HB & TaqMan & OSC & 193 & 383 &  & Y \\
\hline 2017 & $\mathrm{Hu}$ & Asian & HB & TaqMan & PC & 416 & 416 & rs217727 & $\mathrm{Y}$ \\
\hline 2016 & $\mathrm{Li}$ & Asian & $\mathrm{PB}$ & TaqMan & $\mathrm{CRC}$ & 1147 & 1203 & 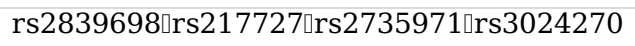 & $\mathrm{Y}$ \\
\hline 2016 & Hua & Asian & HB & TaqMan & $\mathrm{BC}$ & 1049 & 1397 & 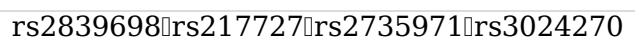 & $\mathrm{Y}$ \\
\hline 2016 & Gong & Asian & HB & TaqMan & $\mathrm{LC}$ & 496 & 206 & rs2839698ロrs2107425 & $\mathrm{Y}$ \\
\hline 2016 & Xia & Asian & PB & CRS-RFLP & $\mathrm{BCa}$ & 464 & 467 & rs217727 & $\mathrm{Y}$ \\
\hline 2015 & Yang & Asian & HB & TaqMan & GC & 500 & 500 & rs2839698』rs217727 & $\mathrm{Y}$ \\
\hline 2014 & $\begin{array}{c}\text { Barnholtz-Sloan } \\
11\end{array}$ & Caucasian & $\mathrm{PB}$ & Illumina & $\mathrm{BCa}$ & 1225 & 1118 & rs2107425 & Y \\
\hline 2014 & $\begin{array}{c}\text { Barnholtz Sloan } \\
12\end{array}$ & Africa & $\mathrm{PB}$ & Illumina & $\mathrm{BCa}$ & 737 & 658 & rs2107425 & Y \\
\hline 2012 & Butt & Caucasian & $\mathrm{PB}$ & Sequenom & $\mathrm{BCa}$ & 678 & 1355 & rs2107425 & $\mathrm{Y}$ \\
\hline 2009 & Song & Caucasian & $\mathrm{PB}$ & $\begin{array}{c}\text { TaqMan } ₫ \text { Sequenom } \\
\text { MassArray }\end{array}$ & $\mathrm{OC}$ & 5366 & 8538 & rs2107425 & $\mathrm{Y}$ \\
\hline 2009 & Quaye & Caucasian & $\mathrm{PB}$ & TaqMan & $\mathrm{OC}$ & 1460 & 2463 & rs2107425 & $\mathrm{Y}$ \\
\hline 2008 & Verhaegh & Caucasian & $\mathrm{PB}$ & PCR-RFLP & $\mathrm{BC}$ & 177 & 204 & rs2839698』rs217727ロrs2107425 & $\mathrm{Y}$ \\
\hline 2008 & Bhatti & Mixed & $\mathrm{PB}$ & Sequenom & $\mathrm{BCa}$ & 824 & 1073 & rs2107425 & $\mathrm{Y}$ \\
\hline
\end{tabular}

Abbreviation: SOC: source of control; HB: hospital-based; HWE: Hardy-Weinberg equilibrium;

BC: Bladder cancer; BCa: Breast cancer; LC: Lung cancer; HCC: Hepatocellular cancer; OSCC: Oral squamous cell carcinoma;

OSC:Osteosarcoma; PC: Pancreatic cancer; CRC: Colorectal cancer; GC: Gastric cancer; OC: Ovarian cancer;

\section{Figures}


Table 2. Meta-analysis results for the included studies of the association between LncRNA H19 polymorphisms and risk of cancer.

\begin{tabular}{llll}
\hline $\begin{array}{c}\text { Variables No. of } \\
\text { studies }\end{array}$ & Allele model & Dominant model & Heterozygous model
\end{tabular}

\begin{tabular}{|c|c|c|c|c|c|c|c|}
\hline OR $(95 \%$ CI $)$ & $\begin{array}{cc}\mathrm{P} & \mathrm{I}- \\
\text { values squared } \\
(\%)\end{array}$ & OR $(95 \% \mathrm{CI})$ & $\begin{array}{cc}\mathrm{P} & \mathrm{I}- \\
\text { values } & \substack{(\%) \\
(\%)}\end{array}$ & OR $(95 \% \mathrm{CI})$ & $\begin{array}{cc}\mathrm{P} & \mathrm{I}- \\
\text { values } & \substack{(\%) \\
\text { squared }}\end{array}$ & OR $(95 \% \mathrm{CI})$ & $\mathrm{P}$ values \\
\hline
\end{tabular}

\section{GロA}

A vs $\mathrm{G}$

All $131.08(0.98,1.19)<0.001$

(GA+AA) vs GG
GA vs GG

AA vs GG

Source of

control

$\begin{array}{lccccccccccc}\text { PB } & 2 & 1.17(\mathbf{1 . 0 4 , 1 . 3 1 )} 0.347 & <0.1 & 1.02(0.68,1.54) & 0.076 & 68.2 & 0.91(0.53,1.55) & 0.032 & 78.2 & 1.41(1.04,1.91) & 0.290 \\ \text { HB } & 11 & 1.07(0.96,1.20)<0.001 & 74.5 & 1.09(0.95,1.26)<0.001 & 73.2 & 1.08(0.95,1.24) & 0.001 & 67.0 & 1.12(0.89,1.41)<0.001\end{array}$

Method of genotype

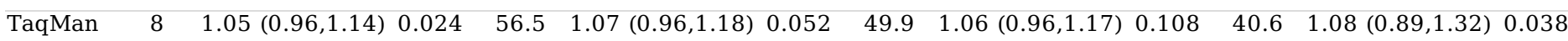

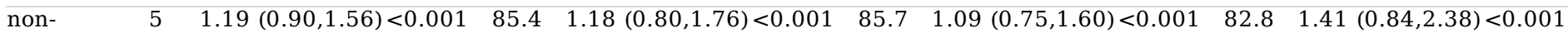
TaqMan

$7727 G \square A$

A vs $\mathrm{G}$

(GA+AA) vs GG

GA vs GG

AA vs GG

All $\quad 15 \quad 1.03(0.94,1.13)<0.001 \quad 70.9 \quad 1.06(0.93,1.22)<0.001 \quad 74.0 \quad 1.07(0.92,1.23)<0.001 \quad 74.1 \quad 1.02(0.85,1.21) \quad 0.002$ Source of

control

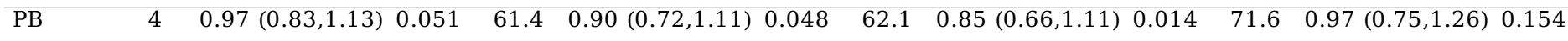

$\begin{array}{llllllllll}\text { HB } & 11 & 1.06(0.94,1.19)<0.001 & 73.1 & 1.14(0.97,1.35)<0.001 & 73.4 & 1.16(0.99,1.37)<0.001 & 69.5 & 1.03(0.82,1.30) & 0.002\end{array}$

Method of genotype

\begin{tabular}{|c|c|c|c|c|c|c|c|c|c|}
\hline TaqMan & 8 & $1.04(0.94,1.15) 0.005$ & 65.5 & $1.13(0.96,1.33)<0.001$ & 74.0 & $1.15(0.97,1.37) 0.056$ & 74.8 & $1.00(0.81,1.23)$ & 0.010 \\
\hline $\begin{array}{l}\text { non- } \\
\text { TaqMan }\end{array}$ & 7 & $0.99(0.80,1.21)<0.001$ & 78.1 & $0.96(0.73,1.27)<0.001$ & 77.6 & $0.94(0.70,1.24)<0.001$ & 76.5 & $1.02(0.72,1.44)$ & 0.020 \\
\hline & & T vs $C$ & & $(\mathrm{CT}+\mathrm{TT})$ vs $\mathrm{CC}$ & & CT vs CC & & & $\mathrm{CC}$ \\
\hline
\end{tabular}

All $\quad 10 \quad 0.96(0.89,1.04) \quad 0.001 \quad 68.5 \quad 0.95(0.85,1.06)<0.001 \quad 71.5 \quad 0.95(0.84,1.07)<0.001 \quad 71.6 \quad 0.97(0.83,1.13) \quad 0.010$

Source of

control

$\begin{array}{llllllllll}\text { PB } & 7 & 0.96(0.88,1.06)<0.001 & 75.8 & 0.92(0.80,1.06)<0.001 & 77.8 & 0.90(0.78,1.03)<0.001 & 75.5 & 1.01(0.85,1.19) & 0.016\end{array}$

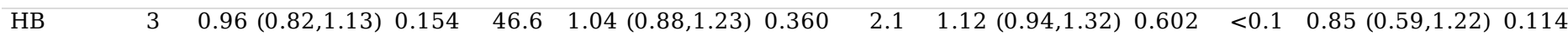
Method of genotype

\begin{tabular}{|c|c|c|c|c|c|c|c|c|c|c|c|c|}
\hline TaqMan & 3 & $0.86(0.80,0.94)$ & 0.396 & $<0.1$ & $0.86(0.71,1.05)$ & 0.098 & 57.0 & $0.90(0.68,1.21)$ & 0.013 & 76.9 & $0.81(0.62,1.04)$ & 0.206 \\
\hline $\begin{array}{l}\text { non- } \\
\text { TaqMan }\end{array}$ & 7 & $1.00(0.91,1.10)$ & 0.004 & 68.9 & $0.99(0.86,1.13)$ & 0.002 & 70.6 & $0.97(0.85,1.11)$ & 0.006 & 66.9 & $1.04(0.87,1.24)$ & 0.028 \\
\hline & & G vs & & & $(\mathrm{AG}+\mathrm{GG}$ & ) vs AA & & AG & AA & & & vs AA \\
\hline
\end{tabular}

\section{A $\square G$}

G vs A

$(\mathrm{AG}+\mathrm{GG})$ vs AA

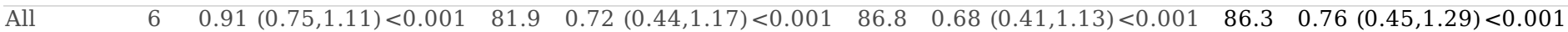
Source of control

PB $\quad \begin{array}{lllllllllllllll} & 1 & 0.89 & (0.77,1.03) & - & - & 0.85(0.71,1.00) & - & - & 0.83(0.70,0.99) & - & - & 0.99(0.63,1.55) & -\end{array}$

HB $\quad 5 \quad 0.92(0.72,1.19)<0.001 \quad 85.5 \quad 0.69(0.35,1.34)<0.001 \quad 85.0 \quad 0.65(0.33,1.29)<0.001 \quad 84.4 \quad 0.71(0.38,1.34)<0.001$

Method of genotype

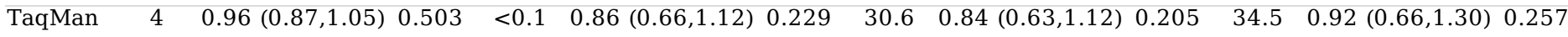

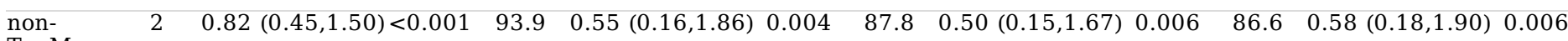
TaqMan

24270 CDG

G vs $\mathrm{C} \quad(\mathrm{CG}+\mathrm{GG})$ vs $\mathrm{CC}$

CG vs CC

GG vs CC

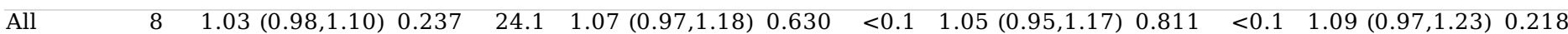

Source of control

\begin{tabular}{|c|c|c|c|c|c|c|c|c|c|c|c|}
\hline PB & 1 & $1.11(0.99,1.25)$ & - & - & $1.06(0.90,1.26)$ & - & - & $0.99(0.82,1.18)$ & - & - & $1.28(1.01,1.61)$ \\
\hline HB & 7 & $1.01(0.95,1.08)$ & 0.293 & 17.9 & $1.07(0.95,1.20)$ & 0.513 & $<0.1$ & $1.09(0.96,1.23)$ & 0.809 & $<0.1$ & $1.04(0.90,1.19) 0.297$ \\
\hline
\end{tabular}


Method of genotype

\begin{tabular}{|c|c|c|c|c|c|c|c|c|c|c|c|}
\hline TaqMan & 5 & $1.08(1.01,1.16)$ & 0.873 & $<0.1$ & $1.12(1.00,1.26)$ & 0.788 & $<0.1$ & $1.08(0.96,1.22)$ & 0.622 & $<0.1$ & $1.21(1.05,1.39)$ \\
\hline & 3 & $0.93(0.84,1.03)$ & 0.309 & 14.9 & $0.95(0.79,1.14)$ & 0.532 & $<0.1$ & $0.99(0.82,1.20)$ & 0.763 & $<0.1$ & $0.88(0.71,1.08)$ \\
\hline
\end{tabular}

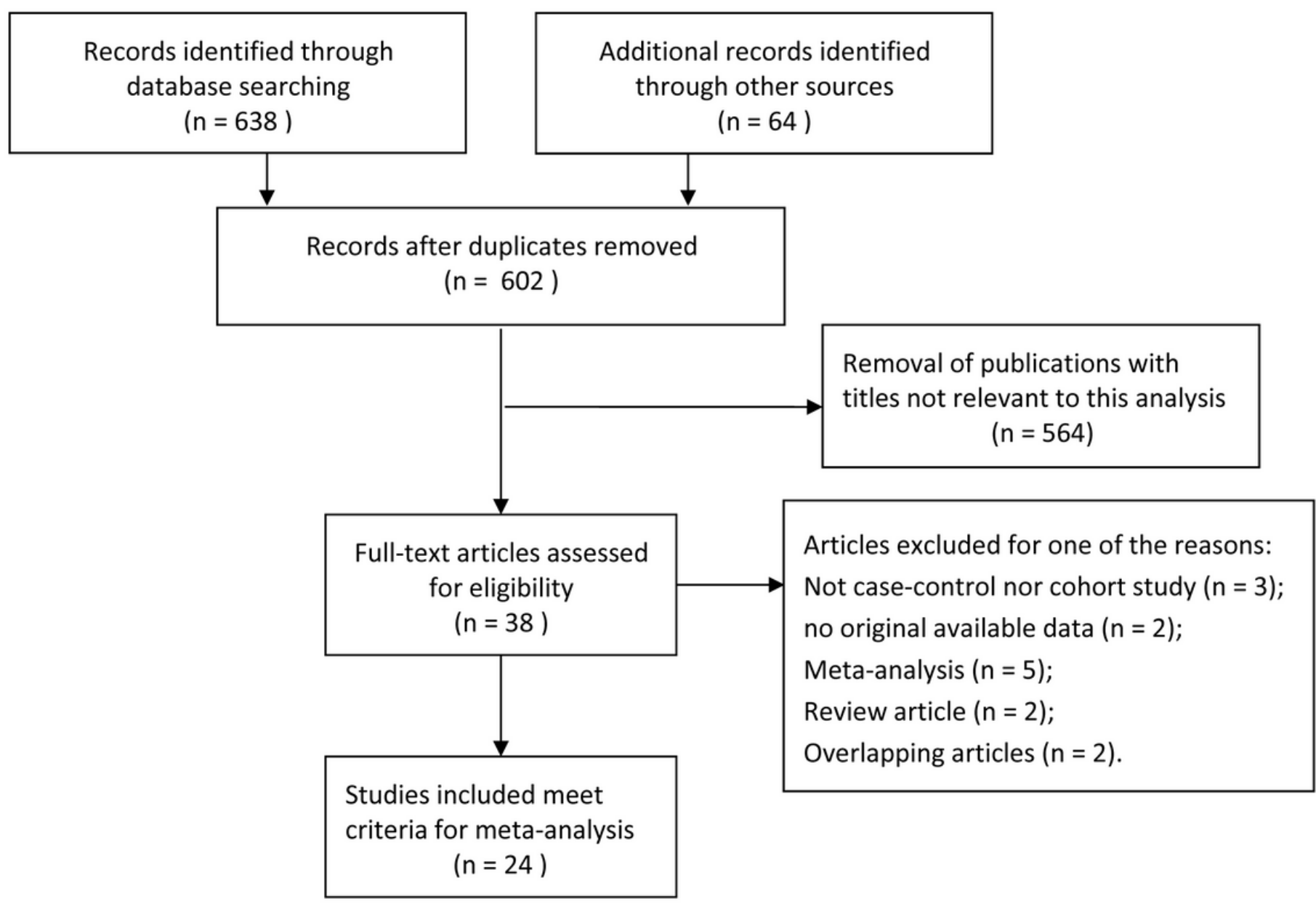

Figure 1

The flow diagram of literature retrieval and screening process. 

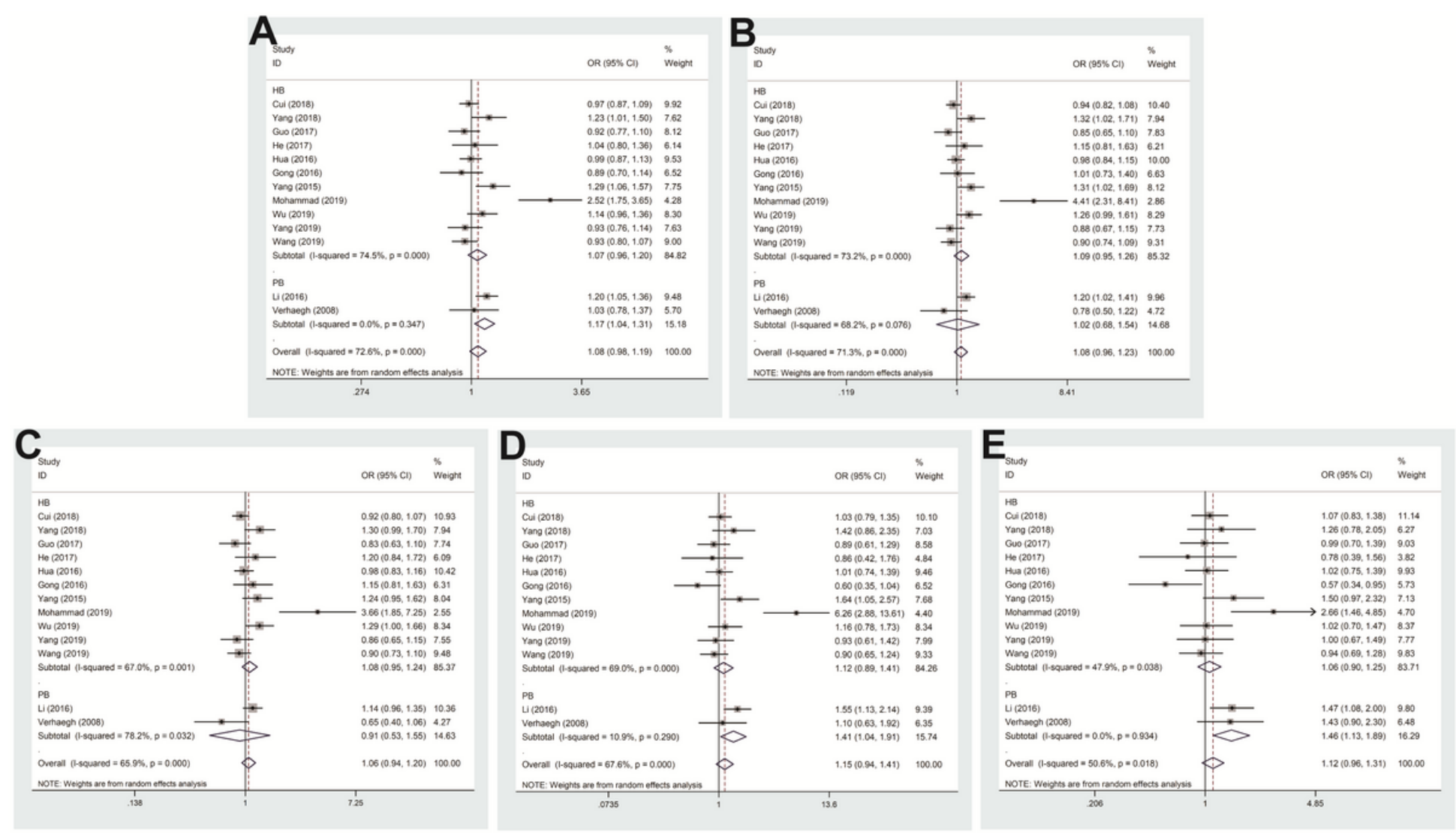

Figure 2

Forest plot of the association between $\mathrm{H} 19$ polymorphism rs2839698 G $\triangle \mathrm{A}$ and cancer susceptibility under five genetic model. A: allele; B: dominant; C: heterozygote; D: homozygote; $\mathrm{E}$ : recessive.
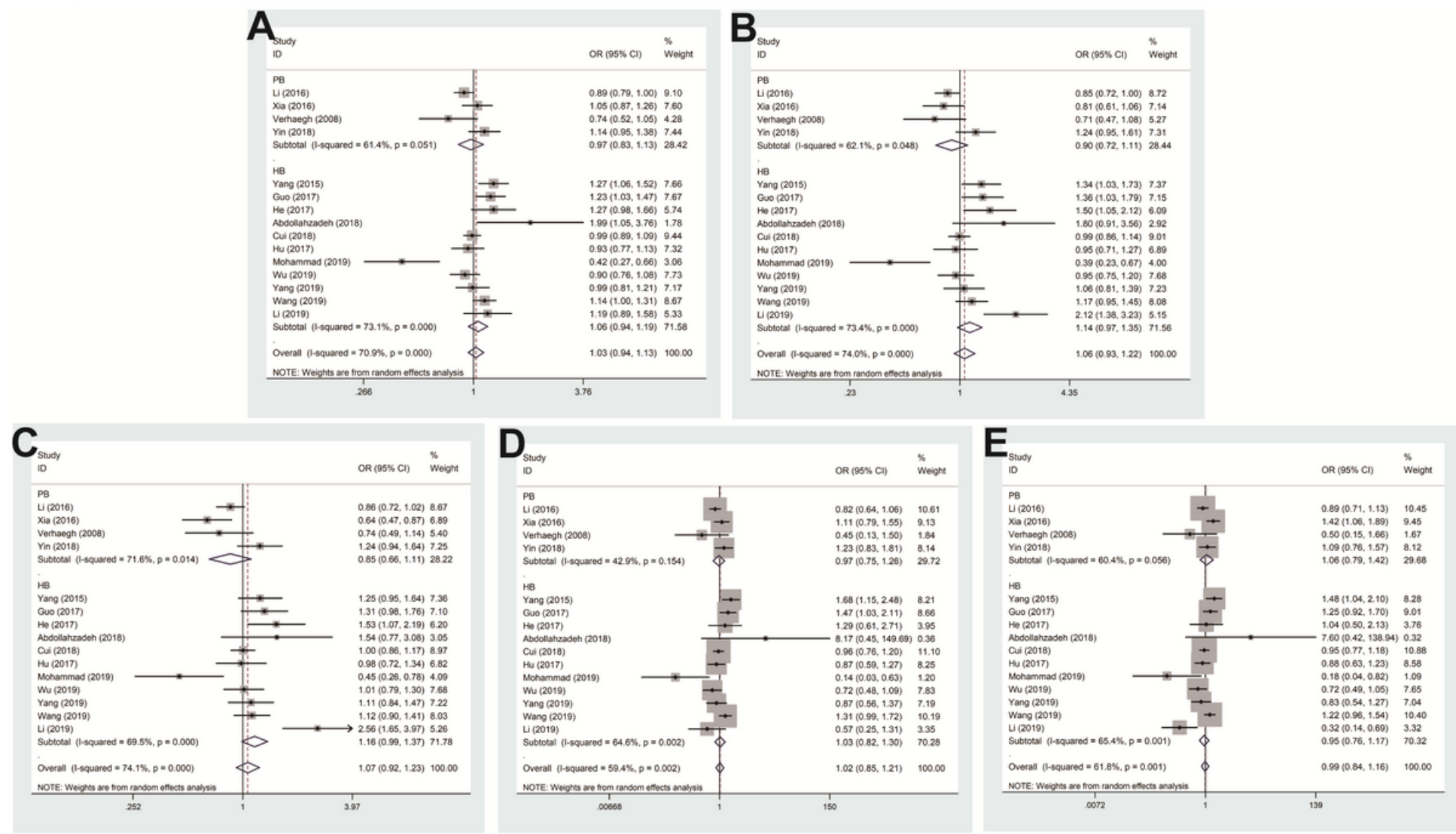

Figure 3 
Forest plot of the association between H19 polymorphism rs217727 G区A and cancer susceptibility under five genetic model. A: allele; B: dominant; C: heterozygote; D: homozygote; E: recessive.
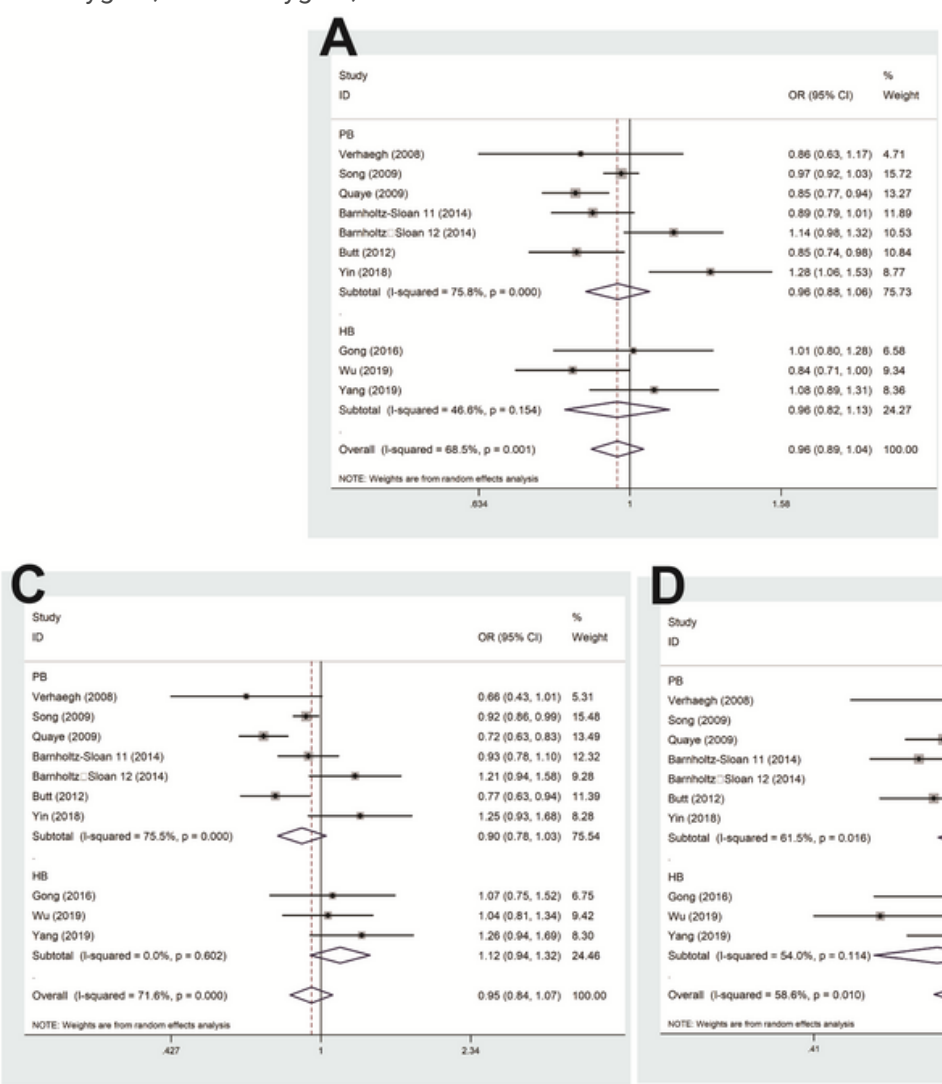
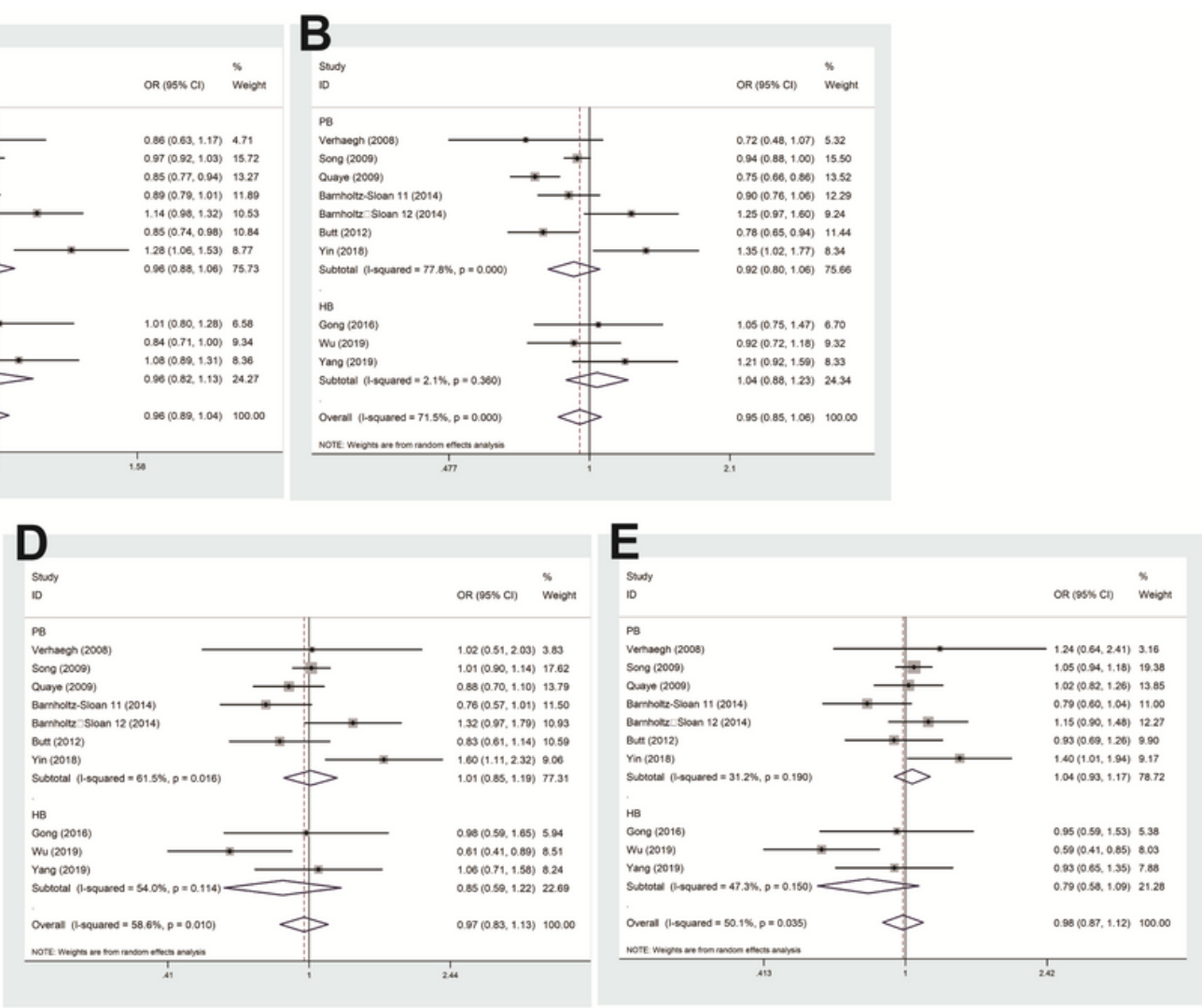

\section{Figure 4}

Forest plot of the association between $\mathrm{H} 19$ polymorphism rs2107425 C $\varangle \mathrm{T}$ and cancer susceptibility under five genetic model. A: allele; B: dominant; C: heterozygote; D: homozygote; E: recessive.
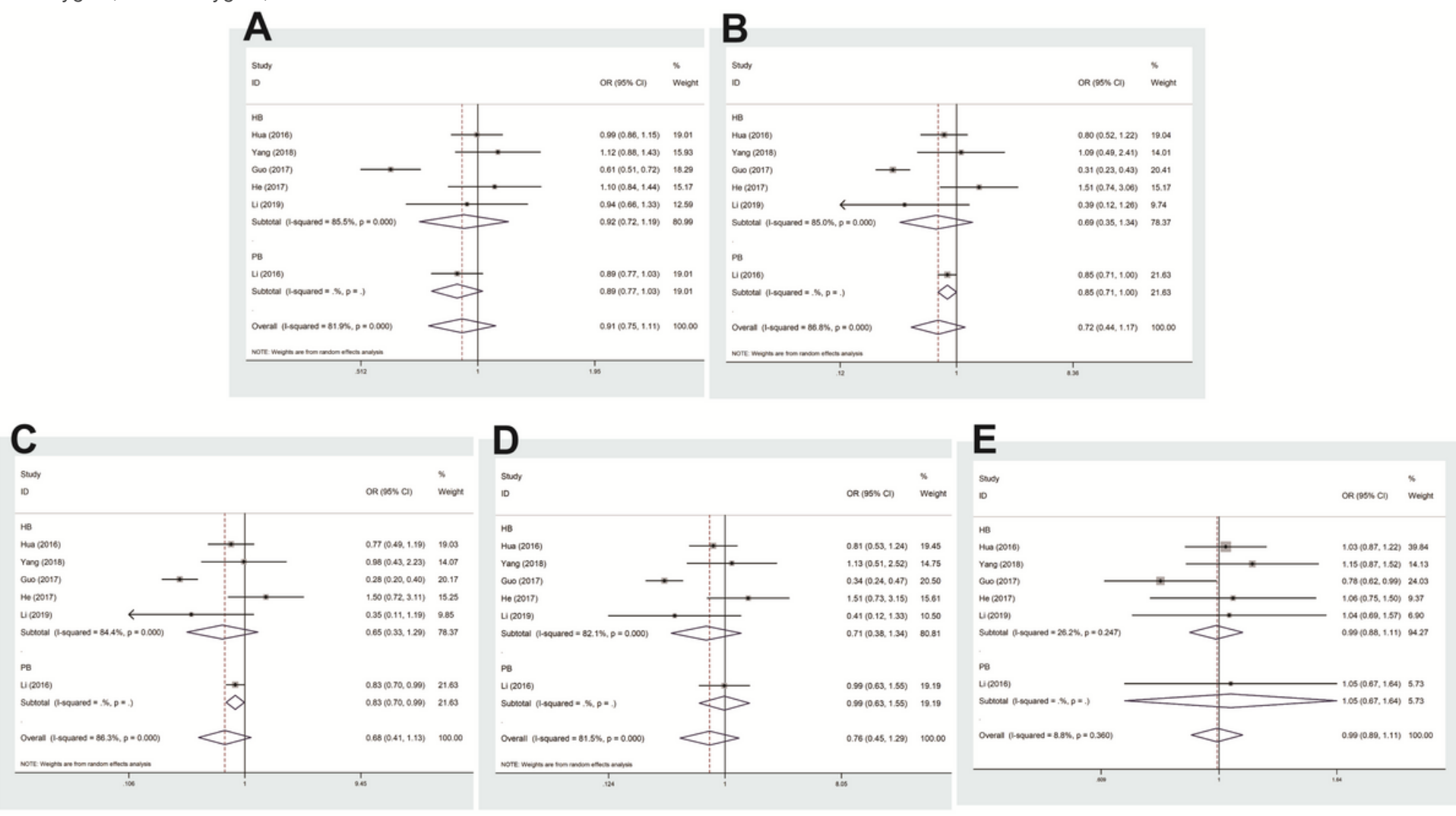

Figure 5 
Forest plot of the association between $\mathrm{H} 19$ polymorphism rs2735971 A囚G and cancer susceptibility under five genetic model. A: allele; B: dominant; C: heterozygote; D: homozygote; E: recessive.
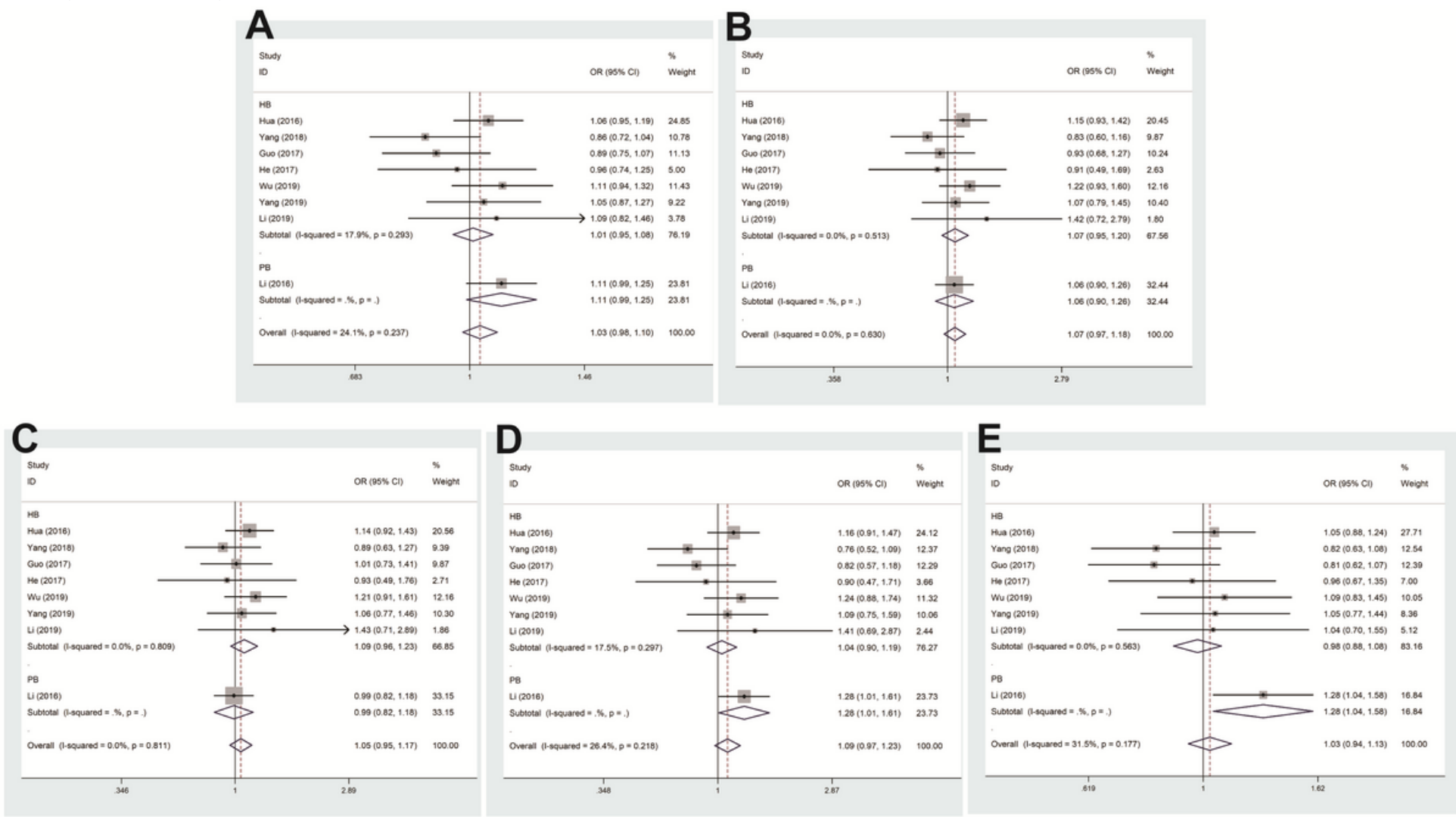

\section{Figure 6}

Forest plot of the association between $\mathrm{H} 19$ polymorphism rs3024270 C $\llbracket \mathrm{G}$ and cancer susceptibility under five genetic model. A: allele; B: dominant; C: heterozygote; D: homozygote; E: recessive.
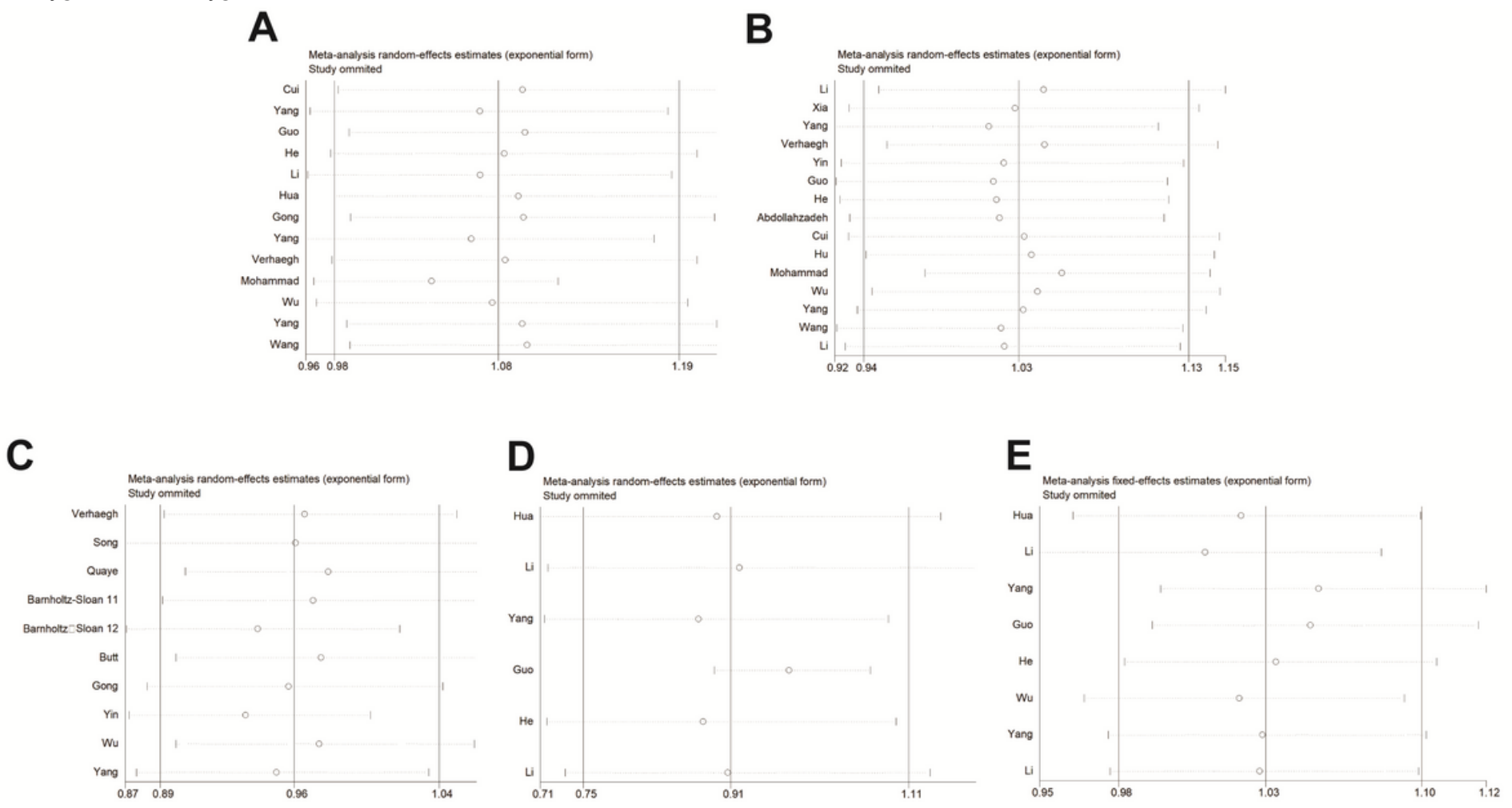

Figure 7 
Sensitivity analysis under the allele model. A: rs2839698; B: rs217727; C: rs2107425; D: rs2735971 ; E: rs3024270.

A
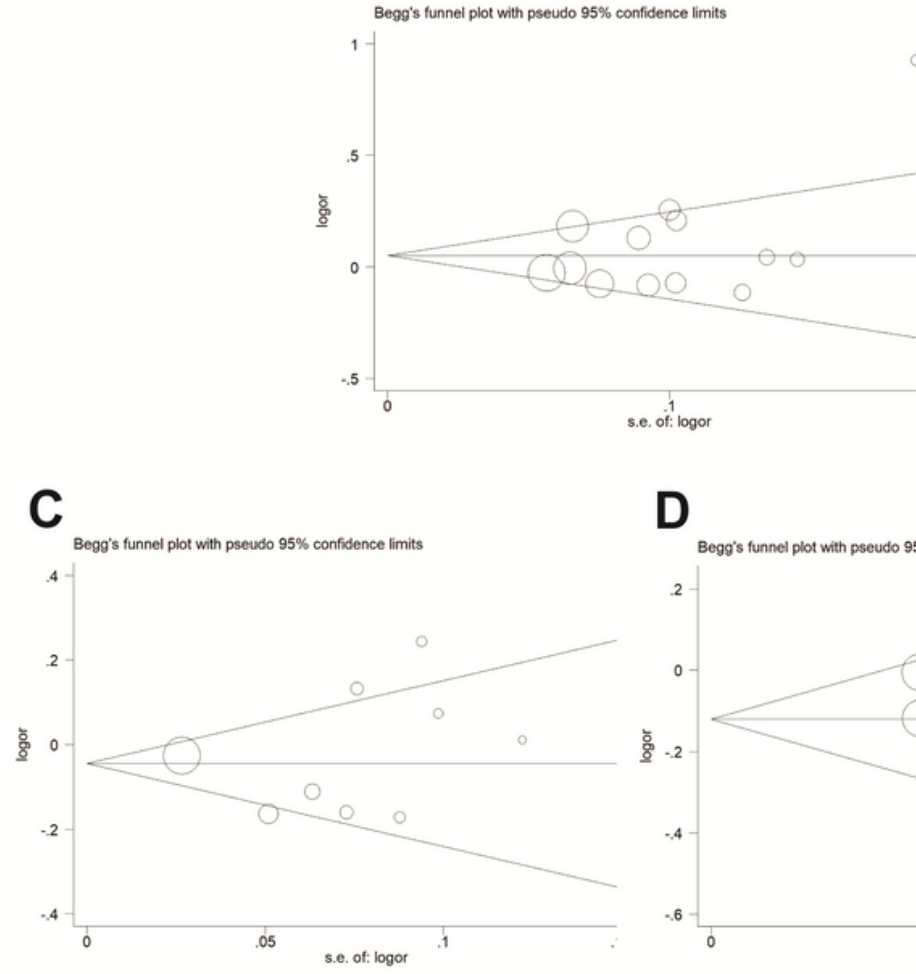

B

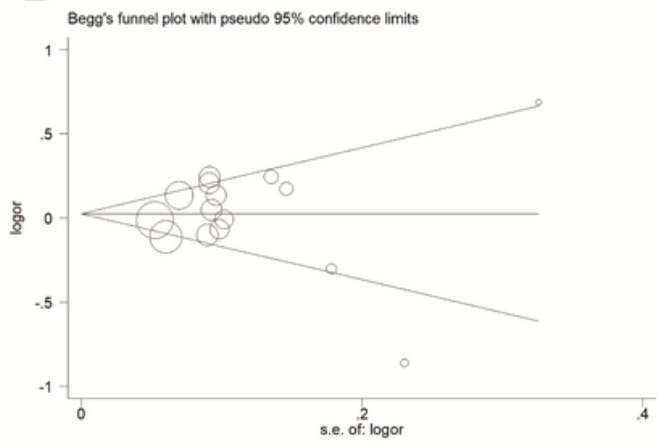

D

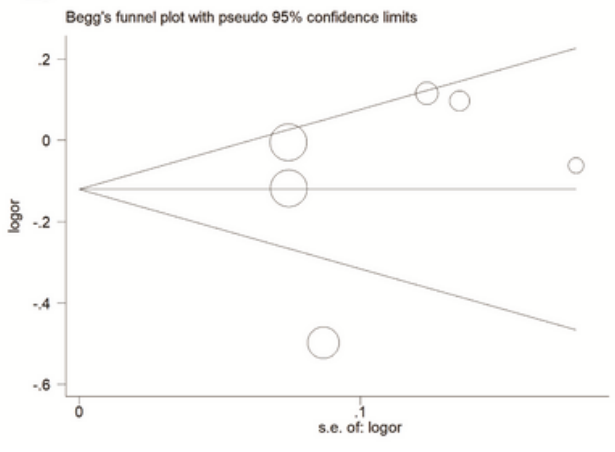

E

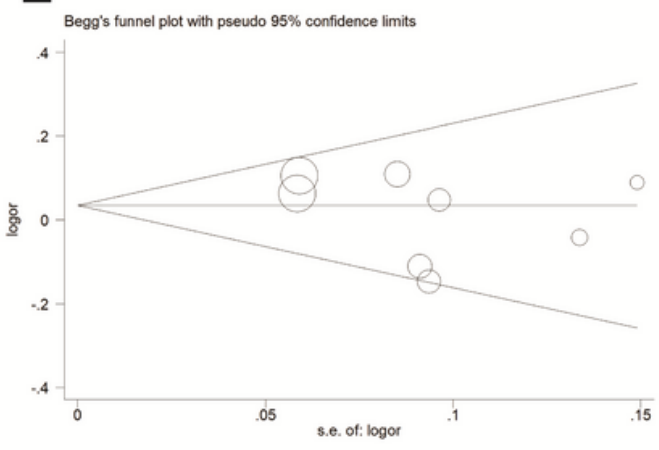

Figure 8

Begg's funnel plot of publication bias test in the allele model. A: rs2839698; B: rs217727; C: rs2107425; D: rs2735971; E: rs3024270.

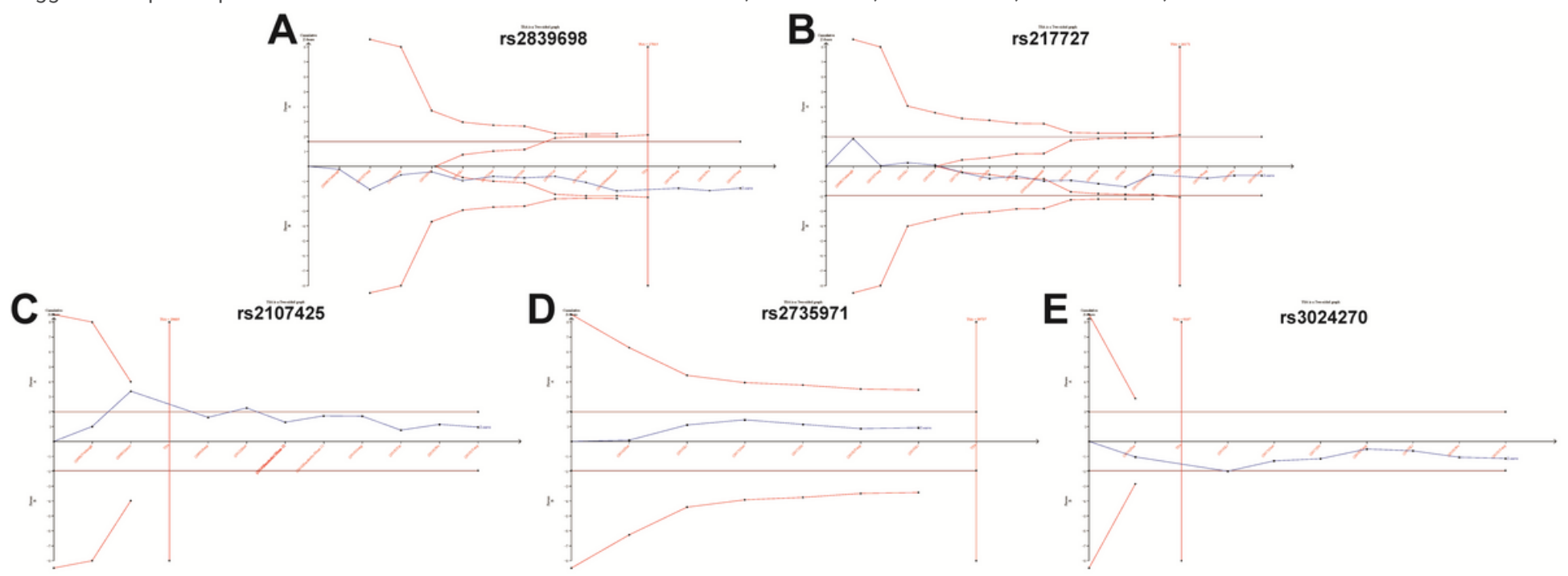

Figure 9

TSA of the association between $\mathrm{H} 19$ polymorphisms and the susceptibility to cancer. The calculation of the required information size was based on a 2-sided $a=5 \%, \beta=15 \%$ (power $85 \%$ ), and a relative risk reduction of 20\%. A: rs2839698; B: rs217727; C: rs2107425; D: rs2735971 ; E: rs3024270. 